\title{
UM OLHAR SOBRE AS CONTROVÉRSIAS
}

\author{
CONTROVERSIES AT GLANCE
}

\author{
Graziella Araujo de Oliveira Lapkoski ${ }^{1}$ \\ Jacqueline Andreucci Lindstron ${ }^{2}$
}

\begin{abstract}
Resumo
Inserida no campo de estudos da Linguística Aplicada, a Teoria das Controvérsias apresenta-se como área de pesquisa relativamente recente no mundo e no Brasil. Considerando que todo estudo requer um embasamento teórico, a partir do qual seja possível aprofundar os conhecimentos sobre um ou mais aspectos relacionados a uma área, este artigo tem como objetivo lançar um breve olhar sobre o que são controvérsias e suas características, na primeira parte. Em seguida, algumas dessas principais características serão verificadas na análise de quatro textos, que compõem uma controvérsia sobre a faculdade da linguagem, com destaque para a questão da dicotomia entre faculdade de linguagem de sentido estrito (FLN) e faculdade da linguagem de sentido amplo (FLB). Tal controvérsia se deu entre os pesquisadores Marc D. Hauser, Noam Chomsky e W. Tecumseh Fitch de um lado e Steven Pinker e Ray Jackendoff de outro. Finalmente, apresenta as conclusões sobre a disputa em questão e expõe se as características propostas pelo filósofo Marcelo Dascal se aplicam no caso. As leituras apontam uma área de pesquisa promissora capaz de evidenciar as questões intrínsecas do texto e levar a uma reflexão sobre a função do debate acadêmico para o linguista, além dos limites do texto.
\end{abstract}

Palavras-Chave: Linguística Aplicada. Controvérsias. Filosofia da Linguística. FLN. FLB.

\begin{abstract}
Being part of the field of Applied Linguistics, the Theory of Controversy is presented as a relatively recent area of research in the world and Brazil. Considering that every study requires a theoretical foundation, from which it is possible to deepen the knowledge of one or more aspects of a field, this article aims to launch a brief look at what controversies and their general characteristics are, in the first part. Then, in the second part, it shall verify the existence of some of those characteristics in the analysis of four texts which make up a controversy about the faculty of language, with emphasis on the dichotomy between faculty of language narrow sense and faculty of language broad sense. This controversy took place between researchers Marc d. Hauser, Noam Chomsky, and W. Tecumseh Fitch on one side and Steven Pinker and Ray Jackendoff in the other. Finally, it presents the findings on the dispute in question and explains if the features proposed by the philosopher Marcelo Dascal apply in the case. The readings suggest a promising area of research that is capable of highlighting the intrinsic issues of the text and lead to a reflection on the function of academic debate to the linguist, beyond the bounds of the text.
\end{abstract}

Keywords: Applied Linguistics. Controversies. Linguistic Philosophy. FLN. FLB.

\footnotetext{
${ }^{1}$ Professora do Centro de Línguas e Intereculturalidade - CELIN, da Universidade Federal do Paraná-UFPR. Mestre em Letras, com ênfase em Estudos Linguísticos, pela Universidade Federal do Paraná (UFPR). E-mail: grazi.lapkoski@uol.com.br

${ }^{2}$ Professora do Ensino Superior da Universidade Tecnológica Federal do Paraná, Câmpus Curitiba-UTFPRCuritiba. Mestrado em Linguística pela Universidade Federal do Paraná (1997). E-mail: jlindstron@hotmail.com
} 


\section{Introdução}

Controvérsia, segundo definição do dicionário Houaiss, é uma “discussão, disputa, polêmica referente à ação, proposta ou questão sobre a qual muitos divergem”. Esta definição semântica do termo não permite, no entanto, o entendimento mais profundo do que envolve e caracteriza uma controvérsia. Em especial, porque ela não é uma conversação oral, um diálogo presencial, no qual as interlocuções se dão de forma espontânea, em uma sequência de fala, idealmente ordenada e imediata. Este “diálogo”, embora também aconteça em turnos, transcorre em um período de tempo bem mais longo, como se cada parte protelasse a resposta até um “determinado” momento, ou forma de resposta, ideal. Considerando o fato de que todo estudo requer um embasamento, a partir do qual seja possível aprofundar os conhecimentos sobre um ou mais aspectos relacionados à área em questão, este artigo tem como objetivo lançar um breve olhar sobre o que são controvérsias, na primeira parte. Em seguida, serão apresentados quatro textos, que compõem uma controvérsia, que trata da faculdade da linguagem e apontada a presença de algumas características. Tal controvérsia aconteceu entre os pesquisadores Marc D. Hauser, Noam Chomsky e W. Tecumseh Fitch de um lado (primeiro e terceiro textos), e Steven Pinker e Ray Jackendoff de outro (segundo e quarto textos), conforme a sequência a seguir: The Faculty of Language: What Is It, Who Has It, and How Did It Evolve?; The faculty of language: what's special about it?; The evolution of the language faculty: Clarifications and implications., e finalmente, The nature of the language faculty and its implication for evolution of language (Reply to Fitch, Hauser, and Chomsky).

\section{O que são?}

Controvérsias, conforme já o dissemos, são discussões a respeito de uma ou mais questões divergentes na opinião de dois ou mais indivíduos e que podem ser de natureza diversa, tais como: filosófica, literária, ou científica. Segundo Dascal (1989), a maioria das controvérsias intelectuais acontece por meio de textos escritos. São "trechos elaborados de discurso, muito diferentes das interlocuções espontâneas características dos diálogos face a face” (p. 1). Contudo, elas podem ser consideradas um “quase-diálogo” para o autor, que se utiliza do quadro conceitual da pragmática conversacional para explicá-las. Ele toma como base de análise para sua explicação uma controvérsia filosófica que estudou detalhadamente, e acredita que a análise se aplica a controvérsias de outras classes. 
Em princípio, é preciso admitir que questões filosóficas não têm solução, ou não seriam questões filosóficas. Uma das formas de tratar essas questões é por meio das “controvérsias”. Para Dascal (1989), controvérsias são geradas por diferenças, mas não se resumem a uma única diferença, nem podem ser tratadas como meras divergências de opinião; a discordância geralmente se manifesta em uma variedade maior de aspectos, que se reúnem em torno de uma suposta divergência central. Segundo o mesmo autor, a dificuldade em identificar tais aspectos acontece porque as controvérsias nem sempre ficam no nível semântico, muitas vezes elas extrapolam e atingem um nível de abstração lógica que pode comprometer o entendimento de uma proposta. Assim sendo, o autor entende que é preciso se "libertar“ (p. 2) de todos os problemas de interpretação e de todos os elementos retóricos para que haja uma análise das supostas oposições. Uma interpretação puramente semântica das diferenças não é suficiente para “apreender a natureza peculiar das controvérsias” e pode não dar a devida atenção a todos os níveis de desacordo envolvidos em uma controvérsia, segundo ele. Sendo assim, sem descartar totalmente a semântica, cujo significado não é tudo, mas parte do todo, e considerando que há relação entre a pragmática e a semântica, Dascal (1989) entende que uma abordagem pragmática, que leva em conta os usos da linguagem, pode oferecer uma teoria mais adequada para a análise das controvérsias. O autor recomenda que uma controvérsia tenha pelo menos quatro textos. Ele sugere que a controvérsia se estabeleça a partir de um texto gerador e pelo menos outros três textos (um texto gerador - uma proposta, uma primeira resposta ao texto gerador - a oposição, uma réplica à segunda proposta e uma tréplica - outra oposição). Tais textos vão lançando novos olhares a certos aspectos e definindo certos territórios de domínio dos autores, de acordo com o que cada texto demanda dentro desses territórios.

Segundo Grice (In: DASCAL, 1982) numa conversação existe uma série de demandas globais e uma série de demandas locais, que constrangem as contribuições em uma conversação. Isso deve ser assim, pois nossas conversas não poderiam ser uma sucessão de comentários desconexos, uma vez que não seriam racionais se fossem. Considerando uma conversação um jogo de cooperação, as demandas globais seriam, por exemplo, o tópico em discussão ou o grau de formalidade da conversação; e as demandas locais seriam, por exemplo, a sequência das perguntas e respostas da conversa. Este modelo teórico considera as conversas como esforços cooperativos em que os participantes fazem suas contribuições conversacionais convencionalmente. Tais convenções estabelecem que, para uma conversa ser bem sucedida, ela precisa atender às quatro máximas da comunicação: a da quantidade, a da qualidade, a da relevância e a de modo. A saber: a máxima de quantidade garante que só se 
deve falar o suficiente, nem mais nem menos do que foi requisitado; a da qualidade diz que só se deve afirmar aquilo que for verdade, não se deve afirmar, portanto, aquilo que não possui evidências; a da relevância expressa que o enunciado deve ser importante para o tópico abordado e que este deve ser mantido e; a máxima de modo afirma que se deve ser claro nas enunciações, evitar ambiguidades e expressões obscuras e não ser prolixo.

Segundo Dascal (1989, p. 305), do mesmo modo que a conversação, a controvérsia também pode apresentar

uma organização hierárquica das demandas... e é plausível afirmar que uma controvérsia se desdobra em um padrão entrecruzado de demandas que os contendores tentam primeiro identificar e em seguida atender com lances sucessivos que, por sua vez, estabelecem novas demandas, e assim por diante.

O mais importante aqui é salientar que as avaliações que cada participante faz em cada lance se refere à sua interpretação pragmática do tópico. Contudo, diferentemente das conversas, onde a "identificação das demandas conversacionais e do processo de interpretação pragmática corre de modo tranquilo e tácito, nas controvérsias ambos são quase sempre problematizados” (DASCAL, 1989, p.305); o que faz com que as questões levantadas sejam postas em um debate.

Outro ponto interessante de ser observado e relevante para nossa análise, porque recorrente, é a repetida argumentação de que um dos participantes não respondeu (satisfatoriamente) ao outro. É comum que sejam alegadas uma suposta má vontade e/ou incapacidade do outro de discutir o assunto com a clareza ou profundidade esperada. A máxima da relevância pode ser, neste caso, usada como argumento de que o oponente não respeita esta máxima, por não se ater ao que está sendo discutido, ou de acordo com Dascal (1989) ao “estado da questão”.

As controvérsias são prolíferas também em alegações de mal-entendido. Ganhar é o objetivo final do jogo e para tal, “qualquer pessoa que decida tomar parte de uma controvérsia toma para si, como oponente, a obrigação de criticar a posição do outro da maneira mais eficaz possível e, como defensor, a obrigação de defender seus próprios pontos de vista de maneira decidida e completa” (DASCAL, 1989, p. 10). Esse compromisso de ganhar traz consigo um aspecto existencial profundo. O que está em jogo é a reputação dos contendores e os envolvidos buscam argumentos para que haja reconhecimento do seu ponto de vista pela comunidade. 
No campo da ciência que podemos verificar uma sequência de controvérsias. Ao apresentar uma teoria o cientista deve estar pronto para que sua teoria seja falseada, ou seja, posta em prova. Sendo assim, quando teorias são apresentadas a comunidade científica elas são imediatamente falseadas, e quanto mais difícil for falsear uma teoria, mais forte ela será.

O que apoia uma teoria científica, Sem dúvida, é a experimentação. Mas a experimentação, por si só, ou falseia ou corrobora uma hipótese e/ou uma teoria. Segundo Popper, uma teoria será tanto melhor quanto mais propensa for a testes de falseabilidade, pelos quais, obviamente, terá que passar. (MESQUITA FILHO, 2000).

Esse falsear sobre as coisas é a crítica sendo feita através do debate. Uma pesquisa rigorosa sobre a controvérsia encontrada permite determinar a natureza da crise, da diferença e gera uma discussão. A discussão seria a polêmica bem delimitada em busca da harmonização de um impasse. Quando os envolvidos percebem o conflito e buscam argumentos para que haja o reconhecimento de seu ponto de vista pela comunidade, cria-se uma controvérsia e se instaura o diálogo das partes.

Algumas propriedades comuns às controvérsias que podemos citar são o fato de que elas se ampliam rapidamente; apresentam teses coerentes para cada uma das partes, isto é, nada é interpretado a esmo; há questionamentos de partes da teoria ou dela como um todo; apresentam um aspecto hermenêutico, nas recorrentes argumentações de falta de entendimento do outro, alegações de má interpretação, por exemplo.

Podem-se perceber, também, algumas características recorrentes nas controvérsias, tais como: serem abertas (sem serem arbitrárias, posto que elas têm regras); terem vida própria e sem controle do caminho que ela vai percorrer; dificilmente se restringirem a uma única área; revelarem divergências profundas; prepararem o terreno para novas discussões; manifestarem sistematicidade.

Listar uma série de características, apesar de ser elucidativo, pode não ser o bastante para que se consiga de fato compreender a dinâmica de uma controvérsia. Sendo assim, com alguns esclarecimentos sobre a teoria da controvérsia colocados, tentaremos aplicá-la a uma discussão acadêmica sobre a origem da linguagem.

\section{Uma controvérsia em análise}


A controvérsia selecionada para análise, conforme mencionado anteriormente, tem como texto gerador The Faculty of Language: What is it, Who has it, and How did it evolve? ? $^{3}$ escrito por Hauser, Chomsky e Fitch (daqui em diante HCF) e publicado na revista Science em novembro de 2002. Neste texto os autores nos fazem refletir sobre a existência de uma faculdade da linguagem em sentido amplo (FLB) e uma faculdade da linguagem em sentido estrito (FLN). Segundo Leite e Franchetto (2004, p. 43), na primeira

\begin{abstract}
há mecanismos presentes nos animais não-humanos, como o sistema sensorialmotor, que permite a compreensão (auditiva) e a produção (articulatória) da linguagem, e o sistema conceitual-intencional, que associa expressões a significados e a intenções comunicativas. Na faculdade da linguagem em sentido estrito, há um sentido computacional único e exclusivo da linguagem humana, a recursividade, produto recente da evolução linguística.
\end{abstract}

Este mecanismo possibilitaria que a linguagem humana criasse construções infinitas a partir de meios infinitos, uma vez que considera cada frase humana uma nova criação, não uma simples repetição: o mecanismo de recursividade permite encaixar construções dentro de outras construções, o que caracteriza um sistema computacional. Não havendo diferenças significativas entre os sistemas recursivos da matemática e a recursão humana.

Os autores sugerem ainda que a aquisição do léxico é exclusivamente humana, mas não discutem como as palavras são escolhidas pela língua e não parecem estar interessados em como esta escolha seria feita. Também não discutem como se dá a evolução da linguagem, uma vez que tem uma visão modular da mesma, ou seja, a linguagem seria um módulo constituído ao nascer do indivíduo, passando a funcionar de uma vez, de pronto, sem condicionamentos da mesma ao contexto social. A faculdade da linguagem seria então inata ao ser humano e não aprendida. Para os autores, o ser humano já nasceria com um dispositivo mental e universal para adquirir e externar a linguagem.

Obviamente tais colocações suscitaram certa polêmica acadêmica e uma das oposições ao texto gerador veio de Pinker e Jackendoff (daqui em diante PJ), na mesma revista Science de agosto de 2004, num artigo intitulado The faculty of language: what's special about it?

Os principais pontos de discórdia entre os dois grupos de autores são a função da linguagem e o que compõe a FLN. PJ começam tentando entender que tipo de sistema biológico seria este que HCF citam e como ele se relacionaria com os outros sistemas humanos e de outras espécies e tentam refutar de vez a hipótese de recursão de HFC.

\footnotetext{
${ }^{3}$ Apresentaremos de forma breve o assunto tratado neste texto. Para melhor entendimento, sugerimos a leitura do texto na íntegra, que pode ser encontrado em mídia eletrônica. Ver referência completa nas referências bibliográficas.
} 
Começam as diferenças. Na oposição ao texto gerador, ambos os autores aceitam que exista uma FLB e uma FLN, mas veem ambas de modo diferente. Eles propõem que a faculdade da linguagem em sentido amplo inclua tudo que seja linguagem, humana ou não. Enquanto a faculdade da linguagem em sentido estrito conteria toda uma série de processos evolutivos da linguagem e não só a recursividade. O problema é que PJ dizem que a linguagem evoluiu e que é preciso definir o que faz parte da FLN, enquanto para HCF a linguagem surge como herança genética, não tem a ver com o meio e a FLN é composta unicamente da recursividade.

PJ discordam da ideia de HCF, apresentada no primeiro texto, de que apenas a recursividade sintática é o aspecto da linguagem que pode ser considerado unicamente humano e unicamente linguístico. Segundo os dois autores, HCF não consideram aspectos como a fonologia, a morfologia, caso, concordância, entre outros. Neste texto, para analisar quais aspectos da linguagem são unicamente humanos e unicamente linguísticos, PJ propõem que a questão fundamental no estudo da faculdade da linguagem humana é "que tipo de sistema biológico ela é, e como ela se relaciona com outros sistemas na nossa espécie e em outras”. (PINKER e JACKENDOFF, 2005, p.202).

Outro questionamento feito pelos autores é o da dificuldade ao tentar detectar quais partes da habilidade de produção oral seriam específicas da fala e quais seriam específicas de outras habilidades mais genéricas, como o entendimento da organização do mundo, por exemplo, e o fato de que as palavras são unidades usadas especificamente na linguagem, mas os pulmões têm outras funções além da de participar no ato da fala (PINKER e JACKENDOFF, 2004, p.202). O mesmo podemos dizer em relação à língua, que além da fala, exerce funções na mastigação, por exemplo.

Um terceiro ponto seria tentar delimitar qual/quais aspectos da capacidade da linguagem são exclusivamente humanos e quais seriam compartilhados com outros grupos de animais. (p.202) Partindo de tais questões, os autores analisam os aspectos citados acima, seguindo a ordem das proposições apresentadas no texto de HCF.

O primeiro aspecto analisado é a estrutura conceptual. PJ concordam com a afirmação de HCF de que a estrutura conceptual dos humanos se sobrepõe parcialmente com a dos outros primatas, isto é, que alguns aspectos desta estrutura são característicos dos humanos e que os primatas conseguem de alguma forma demonstrar seu entendimento de conceitos do mundo, por exemplo. Mas argumentam que tais aspectos fariam parte de um sistema de racionalização não linguística sobre o mundo PJ afirmam também que há uma série de 
sistemas de parentesco e papéis sociais formais que são especificamente humanos e devem ser considerados.

O segundo aspecto é a percepção da fala. PJ dizem que a percepção da fala nos humanos é diferente da percepção de eventos auditivos (sons diversos), isto é, humanos discriminam fonemas. HCF, porém, não discutem esta questão das diferenças de percepção da fala entre os humanos e os outros primatas, no primeiro texto. Eles simplesmente reconhecem a existência de uma percepção auditiva genérica nos primatas.

HCF sugerem que a anatomia humana do trato vocal pode ter sido selecionada mais por exagero de tamanho do que pela evolução da fala. PJ, a respeito da produção da fala, terceiro aspecto analisado, dizem que o aprendizado vocal e a imitação vocal são exclusivamente humanos e manifestados apenas pela fala, com início no balbuciar silábico espontâneo das crianças. Eles alegam que HCF tentam desmerecer a diferença entre humanos e primatas, dizendo que imitação vocal não é característica exclusivamente humana. Contudo, PJ reconhecem que os pássaros, por exemplo, também apresentam certa capacidade análoga para o aprendizado da linguagem. Assim sendo, como teria se desenvolvido essa faculdade da fala? Teria sido uma seleção natural?

O quarto aspecto analisado, fonologia, é uma grande controvérsia entre o texto gerador e a sua primeira resposta. PJ afirmam que ter o potencial para articular os sons da fala não é o mesmo que ser capaz de produzir os sons de uma língua. Segundo eles, os aspectos silábicos e segmentais das estruturas fonológicas não são recursivos e sim um nível diferente de organização de cada uma das línguas humanas. Sendo assim, eles concluem que a fonologia representa um importante contraponto à hipótese da recursividade de HCF. Os autores se declaram surpresos com o fato de HCF não mencionarem o assunto. Declarações como esta são bastante comuns nas controvérsias.

Com relação ao quinto aspecto, o léxico, HCF defendem a hipótese de que é unicamente humano, mas não discutem como as palavras são perfeitamente apropriadas para a linguagem. Para eles, a aquisição de vocabulário faz parte da FLB, enquanto para PJ ela faz parte da FLN. Estes últimos argumentam que as palavras são constituídas por informações gramaticais, têm que ser aprendidas e são uma parte distintiva da linguagem específica do conhecimento humano. Além disso, eles lembram que o léxico é uma combinação de fonologia e estrutura conceptual; os significados são definidos pela relação da palavra com outras palavras, não apenas da palavra com um conceito. Para PJ, o fato de que boa parte do conhecimento lexical envolve informações manipuladas pela sintaxe recursiva torna difícil aceitar que “a capacidade de aprender e representar palavras é parte de um sistema de 
conhecimento geral que evoluiu independentemente das demandas da linguagem" (PINKER e JACKENDOFF, 2005, p.215), como afirmam HCF. Sobre este aspecto, PJ apontam uma tentativa de resolução da contradição de HCF, que em trabalhos anteriores consideravam o léxico como sendo parte da FLN.

O sexto e último aspecto analisado é a estrutura sintática. PJ defendem o ponto de vista de que a sintaxe funciona como um regulador no sistema da linguagem; isto é, "ela ajuda a determinar como os significados das palavras são combinados nos significados das frases e sentenças.” (PINKER e JACKENDOFF, 2005, p.215) Eles apontam que as diferentes línguas se baseiam neste mecanismo, em diferentes graus, para atribuição de significados e transmissão de mensagens. HCF, no entanto, não discutem vários desses aspectos (e.g. caso, concordância, entre outros). Eles se limitam a argumentar que a recursividade é especificamente humana e dizem que não há distinção entre os sistemas recursivos matemáticos e o tipo de estrutura recursiva encontrado na linguagem humana.

Ao término do segundo texto os ânimos parecem estar acirrados entre as partes e os autores do texto gerador escrevem sua réplica "The evolution of the language faculty: clarifications and implications”, publicado na revista Science de fevereiro de 2005.

Conforme mencionado anteriormente, para que uma controvérsia se caracterize são necessários, pelo menos, quatro textos e, consequentemente, o interesse dos autores em dar continuidade à discussão. HCF afirmam que "os comentários de PJ sobre MP [Programa Minimalista] são deveras irrelevantes para a maioria dos tópicos de HCF, e que no presente artigo, e devido às restrições de espaço, nós não podemos discuti-los amplamente aqui.” (HAUSER, CHOMSKY e FITCH, 2005, p.183). As críticas feitas por PJ, no entanto, são importantes e dignas de contra argumentação, ou HCF não se dariam ao trabalho de responder tão detalhadamente no terceiro texto da controvérsia, que é classificado no próprio artigo como “discussão”.

Começam as “trocas de gentilezas” já no início do texto quando HCF afirmam que PJ interpretaram mal, ou não entenderam, o texto gerador. Os termos usados nas críticas são cuidadosamente escolhidos: “cometer um erro lógico” em lugar de dizer, simplesmente, “erraram”; “incorreto” em lugar de "errado”; ou dizer que "entenderam mal” em lugar de “não entenderam”; eles também optam por dizer que vão “esclarecer” ao invés de dizer que vão “explicar” ou “ensinar”, por exemplo; mas é possível perceber certo tom de provocação, como na justificativa que HCF dão para terem escrito o primeiro texto, que seria uma predominante confusão sobre a biologia e a evolução da linguagem, que levou a malentendidos entre pesquisadores. 
Eles também acusam PJ de não ter entendido a distinção entre FLN e FLB. O debate passa por uma verdadeira batalha epistemológica sobre a palavra linguagem e seus vários significados. Os autores deixam claro também que a preocupação de PJ com o passado adaptativo da faculdade da linguagem foi equivocada, uma vez que não se pode provar empiricamente nada relativo à mesma e que ela não seria uma alternativa a hipótese de mecanismos por eles apresentada.

Neste texto, a hipótese de que a recursividade está na FLN está enfraquecida. Os autores apresentam a ideia de que a recursividade se aloja em uma das interfaces do sistema. Os autores, porém, nunca deixam claro o que querem dizer com “interface”. A partir de textos anteriores, é possível entender que para Chomsky a linguagem é um sistema computacional, é um conjunto de regras que gera um produto que faz interfaces com os produtos internos, isto é, faz uma interface com o "cognitivo/intencional” e uma interface com o "sensório/motor”. Este sistema computacional é universal, pertence a, e deve funcionar em todas as línguas, e é só isso que parece interessar. Percebemos então que os autores, neste momento, entendem recursividade como interação, mesmo não abrindo mão de seu modelo computacional/ matemático, mas, segundo eles, ela vai ficar por conta da sintaxe.

Além disso, neste terceiro texto ainda, HFC contemplam a fonologia. A produção da fala e percepção da fala que não tinham tido espaço no texto gerador, ganham destaque neste momento. Os autores colocam que a fala pertence à comunicação e fica em uma das tais interfaces já citadas. Entretanto, eles têm dificuldades em auferir a origem da linguagem simplesmente porque não creem ser possível fazê-lo de forma empírica e não estão preocupados com isso. Entendem e aceitam que a linguagem seja estruturadora do pensamento e tem função comunicativa, mas param por aí.

Percebemos certo movimento de cooperação entre as partes, com a tentativa de esclarecer pontos obscuros e responder às críticas uns dos outros, até porque ambas as partes são academicamente fortes e têm raízes arraigadas em terrenos bem sólidos, todos ganham com a discussão. Segundo Dascal (1989) as teorias são melhor elaboradas nas controvérsias, o debate é esclarecedor e vital para as partes, porque defendem interesses que vão além dos conhecimentos acadêmicos. Os esclarecimentos nos levam a discernir e tomar posições como leitores, escolhendo os argumentos que mais nos agradam tomamos partido na disputa.

O quarto e último texto da controvérsia em questão é “The nature of the language faculty and its implications for evolution of language”, publicado na revista Science de abril de 2005, Pinker and Jackendoff começam elogiando HCF e as contribuições de seu trabalho. Os autores afirmam, novamente, que a raiz de toda a incompreensão reside na distinção entre 
FLN e FLB. Eles dizem ter interpretado a palavra "unique” (único, no sentido de exclusivo, em inglês) (p. 214) de formas diferentes e esta diferença teria gerado os mal-entendidos. Segundo os autores, HCF interpretaram “unique” em termos absolutos de ser exclusivo, assim a faculdade da linguagem em sentido estrito seria restrita ao ser humanos, exclusiva. PJ por sua vez, interpretaram "unique” de forma gradual, entendendo que uma característica pode apresentar diferentes propriedades ao longo de sua história. Ou seja, os autores têm teorias de evolução da linguagem diferentes, PJ são evolucionistas e HCF não. Daí em diante as comparações vão ficando mais brandas, uma vez exposta essa diferença de conceituação. Neste texto, a ideia, isto é, a hipótese de recursividade vai perdendo a força. Além disso, é perceptível que o nível de discussão é outro e o tratamento é extremamente respeitoso. No final, PJ dizem aplaudir “o trabalho experimental de Hauser e Fitch e os novos esforços de Chomsky para conectar suas teorias de gramática às teorias evolucionistas” (PINKER e JACKENDOFF, 2005, p.224). Os autores concluem dizendo que as dicotomias apresentadas no debate são provenientes de diferentes interpretações dos mesmos temas.

\section{Considerações finais}

O que podemos concluir deste debate todo é que houve, sem dúvida nenhuma, a clarificação das divergências na medida em que os textos foram sendo escritos e publicados.

Não houve a conciliação dos opostos porque ao término do debate, após a publicação do último texto, nenhuma das partes havia retrocedido. Muito embora ambas reconheçam que pesquisar mais sobre o assunto, especialmente sobre distinção entre a FLN e FLB se faz necessário. Além disso, como dito anteriormente, controvérsias não têm solução, ou não seriam controvérsias. Também não houve emergência de ideias inovadoras, todos os argumentos apresentados já faziam parte do grande debate, mas isso não tira o brilho dos textos, pelo contrário, pois é no debate que a comunidade acadêmica toma conhecimento de questões que poderiam passar batido e se posiciona.

Pudemos observar como a teoria das Controvérsias apresentada por Dascal pode se aplicar a um debate acadêmico de alto nível, mostrando que nem sempre os argumentos são lógicos e empíricos, muitas vezes se assemelha mais a uma conversa, uma discussão humana.

É digno de nota, como apontado algumas vezes neste texto, o tipo de argumentação recorrente nas controvérsias, na tentativa de se defender de determinadas críticas, ou de chamar a atenção para o "equivoco” do outro. Quer usando termos mais brandos, quer mais rigorosos, é comum encontrar afirmativas como: eles não entenderam; eles descaracterizaram 
o que dissemos; o que eles dizem é irrelevante; eles estão enganados; sua percepção é imprecisa e incompleta; entre outras tantas. A este respeito, Dascal (1989, p.309) afirma que “em uma controvérsia, a capacidade e a boa vontade do oponente de compreender de modo adequado o que é dito ‘de modo tão claro’ são constantemente questionadas”.

Da mesma forma, é possível perceber o alto nível da discussão, caracterizado pelas assunções dos próprios enganos, como HCF fazem ao admitir que PJ estavam corretos quanto à sua análise imprecisa dos resultados de uma pesquisa. Da mesma forma, PJ assumem, no quarto texto, que há duas possibilidades de interpretação da FLB e FLN e que eles estão interpretando diferente de HCF.

É interessante notar que, no desenvolvimento da controvérsia, várias questões e conceitos vão sendo esclarecidos para a plateia deste “quase-diálogo" (como é o caso da definição da FLB e FLN na controvérsia analisada). Esta plateia, embora não intervenha e não participe diretamente, está sempre em cena e, muitas vezes, recebe o apelo direto e/ou indireto das partes para que os compreendam e se posicionem a seu favor.

Finalmente, conceitos e questões esclarecidos ou não, participantes ou plateia, é preciso que a interpretação dos textos de uma controvérsia seja pragmática, uma vez que estes textos não são claros e transparentes.

\section{Referências}

DASCAL, M. Compreendendo as controvérsias. 1989 In: Dascal Interpretação e compreensão. Tradução de Márcia Heloisa Lima da Rocha. São Leopoldo: Editora Unisinos, 2006 (capítulo 13) p. 301-313.

DASCAL, M. Epistemologia, controvérsias e pragmática. Revista da SBHC 12; 73-98, 1994. Disponível em: <http://www.sciencemag.org/content/298/5598/1569.full>. Acesso em: 12 out. 2012.

FRANCHETTO, B.; LEITE, Y. Origens da Linguagem. Rio de Janeiro. Zahar, 2004.

GRICE, H. Paul. Lógica e conversação. In: DASCAL, Marcelo (org.). Pragmática problemas, criticas, perspectivas da linguística - bibliografia. Campinas: edição do autor, 1982.

HAUSER, M.; CHOMSKY, N.; FITCH, W.T. 2001. The Faculty of Language: What is it, Who has it, and How did it evolve? Disponível em: <http://www.sciencemag.org/content/298/5598/1569.full>. Acesso em: 11 out. 2012. 
HAUSER, M.;CHOMSKY, N.; FITCH, W.T. 2005. The evolution of the language faculty: clarifications and implications. Disponível em: < http://www.sciencemag.org/content/298/5598/1569.full>. Acesso em: 11 out. 2012.

MESQUITA FILHO, A. Ensaios sobre Filosofia da Ciência. Cap. 5 - Doutrinas Filosóficas e Teorias Científicas. ECC (Espaço Científico Cultural), 2000. Disponível em: <http://www.ecientificocultural.com/ECC2/FilCien/cap05.htm>. Acesso em: 17 out. 2012.

PINKER, S.; JACKENDOFF, R. 2005. The faculty of language: what's special about it? Disponível em: <http://www.sciencemag.org/content/298/5598/1569.full>. Acesso em: 12 out. 2012.

PINKER, S.; JACKENDOFF, R. 2005. The nature of the language faculty and its implication for the evolution of language. Disponível em:

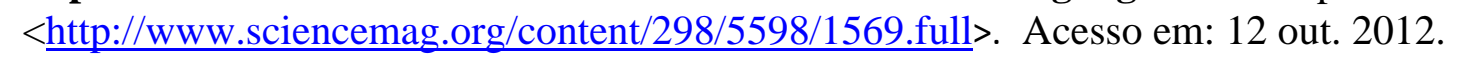

